Sensory and Motor Differences in Autism Spectrum Conditions and Developmental Coordination Disorder in Children: A Cross-

\title{
Syndrome Study.
}

Penny Hannant ${ }^{\mathrm{a}^{*}}$, Sarah Cassidy ${ }^{\mathrm{a}^{*}}$, Rosaline Van de Weyer ${ }^{\mathrm{b}}$, and Sophia Mooncey ${ }^{\mathrm{c}}$.

${ }^{a}$ Centre for Innovative Research Across the Life Course, Coventry University, UK. 'DyspraxiaUK, UK.

'Spire Hospital, UK 


\section{Background}

Successful social integration and communication requires both eloquent conversation skills and the ability to identify, comprehend and execute non-verbal language. Without such skills learning, socialising, behaviour and emotional well-being can be greatly impacted (Lindsay \& Dockrell, 2012; Ratcliffe, Wong, Dossetor \& Hayes, 2015). Thus, in addition to verbal language skills, communication also requires assimilating sensory information from the immediate environment, such as vocal tone, eye contact, facial gesture and posture; planning and executing reciprocal movement effectively (Hannant, Tavassoli \& Cassidy, 2016). Without the ability to carefully process and act upon such information, social understanding, awareness and crucially acceptance can become challenging. Current diagnostic criteria for Autism Spectrum Conditions (ASC) include difficulties with social communication and interaction in addition to unusual motor movement and sensory responsivity (DSM-5, APA, 2013). Since the first pioneering studies of ASC by Kanner (1943) and Asperger (1944), atypical movement and 'clumsiness' has been observed in these individuals. A plethora of research has since demonstrated movement abnormalities in ASC (such as Berkeley, Zittel, Pitney \& Nichols, 2001; Green, Charman, Pickles, Chandler, Loucas, Simonoff, et al., 2009; MacNeil \& Mostofsky, 2012). Moreover, recent findings suggest that the motor impairment present in ASC correlates with the severity of symptoms and may be a marker of the condition (Jansiewicz, Goldberg, Newschaffer, Denckla, Landa \& Mostofsky, 2006; Dziuk, Larson, Apostu, Mahone, Denckla \& Mostofsjy, 2007; Hilton, Wente, LaVesser, Ito, Reed \& Herzberg, 2007; MacDonald, Lord \& Ulrich, 2013; Hannant, Cassidy, Tavssoli \& Mann, 2016). Whilst some research goes further, suggesting that autism is primarily a movement disorder (Leary \& Hill, 1996; Nayate, Bradshaw \& Rinehart, 2005; Whyatt \& Craig, 2012). However, studies have also shown that similar difficulties in social integration and awareness can also occur in individuals with motor impairments without ASC, such as those with a Developmental Coordination Disorder (DCD) (Cantell, Smith \& Ahonen, 1994; Kadesjo \& Gillberg, 1998; Cummins, Piek \& Dyck, 2005; Wang, Tseng, Wilson \& Hu, 2009; Mandich, Polatajko, Macnab \& Miller, 2001; Cassidy, Hannant, Tavassoli, Allison, Smith \& Baron-Cohen, 2016). This study therefore explores the similarities and differences in coordination, sensory responsivity and social behaviours between ASC and DCD children. 
Motor coordination in autism spectrum conditions

Motor coordination difficulties have frequently been observed in ASC (Kanner, 1943; Asperger, 1944; Teitelbaum, Teitelbaum, Nye, Fryman \& Maurer, 1998; Berkeley et al., 2001; Green et al., 2009; MacNeil \& Mostofsky, 2012) and are thought to be present from early infancy. For example, head lag in infants (defined as the head lagging behind the trunk in a pull-to-sit position) (Flanagan, Landa, Bhat \& Bauman, 2012), and persistent asymmetry when lying from as young as 6 months old (Teitelbaum, et al., 1998). Reports also indicate significant parental concerns of motor development between 1 and 2 years of age (Charwarska, Paul, Klin, Hannigen, Dichtel \& Volkmar, 2007). Indeed, a prevalence rate of definite motor impairment within ASC has been estimated, using assessments of coordination, to be approximately $80 \%$ with $10 \%$ borderline (Green, et al., 2009; Miyahara, Tsujii, Hori, Nakanishi, Kageyama \& Sugiyama,1997). A high level of impairment in motor coordination is also noted in a range of other studies (such as Whyatt \& Craig, 2012; Ming, Brimacombe \& Wagner, 2007; Page \& Boucher, 1998; Kopp, Beckung \& Gillberg, 2010). In addition to high prevalence rates of motor coordination difficulties in ASC, individuals with ASC have been reported to have motor skills often falling to 1.5 SDs below the mean when compared to typically developing counterparts (Fournier, Hass, Naik, Lodha \& Cauraugh, 2010).

Motor coordination difficulties are thought to play a fundamental role in social integration and as such have been observed in ASC research. For example, individuals with ASC have been found to have significant impairments in skilled social gestures such as imitation (Mostofsky, Dubey, Jerath, Jansiewicz, Goldberg \& Denckla, 2006). Moreover, studies have significantly correlated motor skills with the severity of autism symptoms (Jansiewicz et al., 2006; Dziuk et al., 2007; MacDonald et al., 2013; Hilton et al., 2007). These studies suggest that impairments in motor coordination interfere with the facilitation of meaningful, goal directed interactions both socially, in the form of non-verbal communication such as expression, proxemics and joint attention, and with the environment.

\section{Motor coordination in developmental coordination disorder}

Since first being recognised as 'clumsy child syndrome' in 1975 (Gubbay, 1975; DSM-3, APA 1987) DCD has been in the prodigious position of having a number of labels including dyspraxia (Denckla, 1984), 'Physical awkwardness' (Wall, Reid \& Paton, 1990) and 
specific developmental disorder of motor function (WHO,1992). For the purposes of this paper DCD terminology will be used to help eliminate any confusion with regards to the terminology and DCD enigma (Gibbs, Appleton \& Appleton, 2007). DCD is a pervasive neurodevelopmental disorder which impacts on the maturation and development of motor coordination. DSM-5 Criteria (APA, 2013) define DCD as having "motor skill deficit that significantly or persistently interferes with activities of daily life appropriate to the chronological age". However, DCD often entails on-going social and academic frustration and can also lead to mental health challenges (Cairney, Rigoli \& Piek, 2013; Kirby, Sugden \& Purcell, 2014; Gagnon-Roy, Jasmin \& Camden, 2016).

Children and adults with DCD have also been shown to have significantly more ASC associated symptoms than those without DCD (Kadesjo \& Gillberg, 1998; Cassidy et al., 2016). Children with DCD generally have significantly lower scores on attention and learning and are less confident with physical and social skills (Dewey, Kaplan, Crawford \& Wilson, 2002; Schoemaker \& Kalverboer, 1990). Adolescents with DCD have been found to have fewer social hobbies and past times and lower academic ambitions (Cantell et al., 1994). A child's motor ability has been found to be a significant predictor of social behaviour (Cummins et al., 2005).

The prevalence rate of DCD is varied (Kadesjo \& Gillberg, 1998; Lingam, Hunt, Golding, Jongmans \& Emond, 2009; Tsiotra, Flouris, Koutedakis, Faught, Nevill, Lane \& Skenteris, 2006), however the European Academy of Childhood Disability (Blank, Smits-Engelsman, Polatajko \& Wilson, 2012) estimates between 5-6\% are the most frequently quoted within the literature. In all children with this condition it is generally recognised that motor coordination difficulties fall below 1.5 SDs from the mean, with 1SD also considered as needing support in many instances (EACD recommendations, 2012; Sugden \& Chambers, 2003; Tsai, 2009).

Similarities between autism spectrum disorders and developmental coordination disorder Children with ASC or DCD are characterised with varying degrees of persistent symptoms of motor coordination and social integration impairment. However, motor coordination is intrinsically linked to sensory feedback, such as the visual and proprioceptive feedback required when planning and executing the motor function of reaching for a cup (Brooks, 1983). Consequently, deficiencies in sensory guidance are likely to play a pivotal role in the development and maintenance of motor coordination difficulties and are also observed 
in both ASC and DCD. Atypical sensory responsivity in ASC has been extensively researched and widely recognised since original studies first described sensory 'intrusions'. The presence of sensory responsivity problems in ASC is high, with $80-95 \%$ of children with ASC having sensory difficulties (Caminha \& Lampreia, 2012; Tomchek \& Dunn, 2007). Additionally, sensory difficulties in DCD have also been demonstrated through a number of research studies (such as: Zoia, Pelamatti, Cuttini, Casotto \& Scabar, 2002; Piek \& Dyck, 2004; Cherng, Hsu, Chen \& Chen, 2007).

Accordingly, there are several similarities between the symptoms observed in ASC and those observed in DCD. This co-occurrence of characteristics has been noted previously by Gillberg and Kadesjo (2010), stating that ASC symptoms were strongly associated with DCD. More specifically Piek and Dyck (2004) stated that deficits in motor coordination are as fundamental to ASC as they are to DCD.

Differences between autism spectrum disorders and developmental coordination disorder Research has examined the processes involved in the motor coordination difficulties in both DCD and ASC, however the evidence regarding the aetiology for each condition remains equivocal. With reference to $D C D$, motor difficulties have been associated with impaired or less well-defined motor imagery (Deconinck, Spitaels, Fias \& Lenoir, 2009) (defined as a dynamic simulation that represents the intended movement internally or mentally in the absence of overt movement (Jeannerod \& Decety, 1995). For example, impaired motor imagery has been shown to affect mental rotation performance (Wilson, Maruff, Butson, Williams, Lum \& Thomas, 2004). However, task complexity and the level of motor impairment also impact coordination in DCD, indicating the atypical feedforward programming as a possible underlying difficulty (Williams, Thomas, Maruff \& Wilson, 2008). Problems in generating programs for volitional movements have been observed by Smits-Englesman, Wilson, Westenberg and Duysens, (2003) and Chang and Yu, (2010) where movement errors were more prevalent in cyclic movements as opposed to discrete tasks. Nevertheless, there are inconsistencies with this hypothesis in that children with DCD have been shown to succeed as well as typically developing children at a procedural sequence learning task (Lejeune, Catale, Willems \& Meulemans, 2013) and have shown some awareness of a repeating sequence pattern in a visuo-motor task (Gheysen, Van Waelvelde \& Fias, 2011). 
A different angle of research has focused on the role of sensorimotor input in DCD. For example, when assessing spatiotemporal gait variables in children with DCD when walking in both light and dark conditions, a greater reliance on the visual feedback was shown, suggesting impairments in proprioception (Deconinck, De Clercq, Savelsbergh, Van Coster, Oostra, Dewiite \& Lenoir, 2006). Children with DCD also appear to have significantly higher thresholds for detecting form coherence patterns (the shape and structure of objects) whilst motion coherence (the speed and direction of an object) remains intact. Form coherence can occur in the absence of visual awareness and so is perhaps more reliant on spatial feedback (Chung \& Khuu, 2014), thus providing evidence for difficulties in processing spatial information (O’Brien, Spencer, Atkinson, Braddick \& Wattam-Bell, 2002). A meta-analysis by Wilson, Ruddock, Smits-Engelsman, Polatajko and Blank (2013), collated results from one hundred and twenty nine studies, concluded that children with DCD had reduced ability to learn motor skills due to a delay in neuromaturation, deficits in feedforward programming, timing and dynamic control of posture.

With reference to ASC, a similar alteration of motor imagery skills has also been considered as a cause for the underlying coordination difficulties in goal-less movements (Conson, Mazzarella, Frolli, Esposito, Marino, Trojano et al, 2013; Hirata, Hideyuki, Kitajima, Hosobuchi, Nakai \& Kokubun, 2015). However, impaired motor imagery appears to be one of few similarities in the underlying causations of motor coordination difficulties. Firstly, no central timing difficulties have been noted in ASC, only irregularities in implementation (Price, Shiffrar \& Kerns, 2012; Rinehart, Bradshaw, Brereton \& Tonge, 2001) and unlike DCD, where difficulties in forming a feedforward program have been explored as a fundamental deficit, research has shown that individuals with ASC are able to form and apply motor programs (Inui \& Suzuki, 1998; Gidley Larson, Bastian, Donchin, Shadmehr \& Mostofsky, 2008; Vandenbrouke, Scholte, Engeland, Lamme \& Kemner, 2009; Gowen \& Hamilton, 2013; Rinehart et al., 2001). Conversely, as opposed to having problems acquiring the feedforward program as in DCD, individuals with ASC are reported to have difficulties harnessing the sensorimotor feedback from the environment necessary to alter or adapt movement and the feedforward program (Vandenbrouke et al., 2009; Gowen \& Hamilton, 2013; Nazarali, Glazebrook \& Elliott, 2009; Dowd, McGinley, Taffe \& Rinehart, 2012). Mosconi suggested that the feedback alterations involved in ASC may be associated with the visual feedback circuits in the cerebellum (Mosconi, Luna, Kay-Stacey, 
Nowinski, Rubin, Scudder et al., 2013). Moreover, much research suggests a higher order visual impairment is related with the coordination difficulties in ASC (Spencer, O'brien, Riggs, Braddick, Atkinson \& Wattam-Bell, 2000; Miller, Chukoskie, Zinni, Townsend \& Trauner, 2014). For example, by exploring luminance sensitivity in high-risk infants with familial risk of ASC, abnormalities in the magnocellular pathway have been highlighted as a possible endophenotypic marker for ASC (the magnocellular pathway is also the input to the amygdala and emotional processing) (McCleery, Allman, Carver \& Dobkins, 2007). Furthermore, abnormalities in the magnocellular pathway in ASC have also been tied to difficulties in motion processing (McCleery et al., 2007). The relationship between motion coherence detection and motor coordination appears to be significant in ASC (Milne, White, Campbell, Swettenham, Hansen \& Ramus, 2006; Price et al., 2012). As well as possible deficits in the visual feedback systems, research has also demonstrated an 'overreliance' on proprioception as a possible compensatory strategy (Masterton \& Biederman, 1983; Izawa, Pekny, Marko, Haswell, Shadmehr \& Mostofsky, 2012). However, arguments for such reliance are diluted with research on proprioception in ASC, such as problems with proprioceptive skills in tiptoeing, pushing objects, running and distinct patterns of proprioceptive processing difficulties (Blanche, Reinoso, Chang \& Bodison, 2012; Siaperas, Ring, McAllister, Henderson, Barnett, Watson et al., 2012). Nonetheless, there is clear evidence that children with ASC are guided differently than controls by sensory stimuli, whether by increased sensitivity to proprioceptive error and a decreased sensitivity to visual error (Marko, Crocetti, Hulst, Donchin, Shadmehr \& Mostofsky, 2015) or by visuotactile input being as equally weighted an input as proprioceptive information (Greenfield, Ropar, Smith, Carey \& Newport, 2015).

To summarise the above, as suggested by Piek and Dyck (2004), one possible way to distinguish between DCD and ASC is to examine the differences in visual-spatial organisation. It would seem that motor coordination difficulties in DCD are related to the formation of a feedforward program, form coherence and spatial processing such as that required for successful proprioception, whilst motor coordination difficulties in ASC appear to be connected to feedback, motion coherence and visual sensitivity. Few studies have explored these differences in aetiology between the two conditions, yet in doing so the foundations, symptoms, diagnosis and remediation of each condition may become closer to being understood. By employing a comprehensive and detailed online questionnaire comprising well tested measures, this study aims to: 1) examine the similarities and 
differences in coordination between DCD and ASC; and 2) examine the similarities and differences in sensory responsivity between DCD and ASC. We hypothesise that there will be limited differences in coordination between the two conditions and that the sensory responsivity will show similarities in most areas with differences in visual responsivity and proprioception.

\section{Method}

\section{Participants}

Participants were recruited via National ASC and DCD support groups and the Cambridge ARC database. A total of 100 children's parents participated in the cross-syndrome online questionnaire. 9 of these did not complete past the initial diagnosis question and 14 children had an additional diagnosis of Attentional Deficit Hyperactivity Disorder (ADHD), which is outside the remit of this study and were excluded. The final numbers for the ASC group comprised of 42 children, (35 male, 7 female) aged 7-21 (mean age $=12.22$ years). The DCD group was comprised of 26 children (19 male, 7 female), aged 7-21 (mean age = 11.06 years), and a third dual diagnosed ASC/DCD group comprised of 9 children (2 male, 7 female), aged 8-15 (mean age $=12.26$ years). ASC criteria was established via the online Autism Quotient validated against the DSM-IV criteria (Baron-Cohen, Wheelwright, Skinner, Martin \& Clubley, 2001). Unfortunately not all participants completed the detailed sensory checklist, decreasing participant numbers for the sensory section of the study to 26 ASC and 18 DCD.

Participants completed an online questionnaire that consisted of parental report measures for three main areas:

autistic traits (Autism Quotient Child Version; AQ-Child; Baron-Cohen et al., 2001), to measure the autism symptoms within both conditions (ASC and DCD) and to ensure that no children in the DCD group had significant levels of autistic symptoms; coordination (Developmental Coordination Disorder Questionnaire '07; DCDQ; Wilson et al., 2007), to measure the level of coordination difficulties present; and finally sensory responsivity (Sensory Profile Checklist Revised second edition; SPCR; Bogdashina, 2016), to identify a detailed sensory profile of each child.

There were significant group differences between the ASC and DCD children in relation to 
autism symptoms. There were no significant group differences in gender ratio and age between the ASC and DCD children. See Table 1 for characteristics of both groups.

Table 1: Demographic descriptives and group comparisons.

$\begin{array}{cccc}\text { Group } & \text { Gender } & \begin{array}{c}\text { Age in } \\ \text { Years }\end{array} & \begin{array}{c}\text { Autism } \\ \text { Quotient } \\ 106.64 \pm 18.2\end{array} \\ \text { ASC } & 35 \mathrm{M} & 12.23 \pm 3.35 & 1 \\ (\mathrm{~N}=42) & 7 \mathrm{~F} & (7.25-21.17) & (56-145) \\ \mathrm{DCD} & 19 \mathrm{M} & 11.07 \pm 3.05 & 68.96 \pm 19.62 \\ (\mathrm{~N}=26) & 7 \mathrm{~F} & (7.67-21.75) & (23-107) \\ & \mathrm{X}^{2}(1,68)= & t(66)=1.44, & t(62)=7.84 \\ & 1.03, & p=001 \\ \text { Difference } & 1.03=.156 & d=1.99 \\ & p=.309 & & \\ & & & \\ \text { ASC/DCD } & 2 \mathrm{M} & 12.27 \pm 2.40 & 106.33 \pm 14.1 \\ (\mathrm{~N}=9) & 7 \mathrm{~F} & (8.08- & 8 \\ \text { Note: }{ }^{*} \text { denotes } p<0.05 & 15.33) & (78-123) \\ \end{array}$

\section{Materials}

Participants completed a battery of self-report assessments, two of which were criterion based with a given cut-off point (AQ-Child and DCDQ) and one of which was intended to give a profile of sensory strengths and weaknesses (SPCR).

The Autism Quotient (AQ; Baron-Cohen, et al., 2001):

The Autism Spectrum Quotient-Children's Version (AQ-Child) is a 50 item parent-report questionnaire that aims to quantify autistic traits in children 4 to 11 years old. Questions are based on mind-reading, attention to detail, social skills and imagination. The range of scores on the AQ-Child is $0-150$ with a cut-off point of 76 thought to show high sensitivity $(95 \%)$ and specificity (95\%) to autism. The AQ-Child is considered to have high test-retest and reliability coefficients, and was validated using the DSM-IV criteria being administered to 540 children with an ASC diagnosis and 540 typically developing controls (Auyeung, Baron-Cohen, Wheelwright \& Allison, 2008). The AQ-Children's version was used in the questionnaire as it was considered the most appropriate to cover the anticipated population age.

The Developmental Coordination Disorder Questionnaire ‘07 
The Developmental Coordination Disorder Questionnaire (DCDQ: Wilson, Kaplan, Crawford \& Roberts, 2007) is a 15 item parent-report questionnaire designed to identify subtle motor problems in children of 5 to 14.6 years of age. Questions are based on fine motor skills, control during movement and general coordination. The range of scores on the DCDQ is 0-75 with cut-off scores for the three age groups showing high sensitivity $(85 \%)$ and specificity $(71 \%)$ being administered to 519 children. The DCDQ showed differences in scores between children with and without DCD $(p<.001)$ provide evidence of construct validity and was validated with the Movement Assessment Battery for Children $(r=.55)$ (Wilson, Crawford, Green, Roberts, Aylott \& Kaplan, 2009).

The Sensory Profile Checklist Revised $-2^{\text {nd }}$ Edition

The Sensory Profile Checklist Revised $-2^{\text {nd }}$ Edition (SPCR: Bogdashina, 2016) is a 312 item parent-report questionnaire designed to robustly profile sensory strengths and weaknesses in order to design specific therapy. It is not a standardised assessment or a criterion based assessment but is well known for its ability to profile sensory responsivity and as such is supported by the Autism Education Trust and the Department for Education. An age range is not given for this checklist as it is designed to profile individual sensory responses. The items on the SPCR are based on seven underlying sensory modalities: visual, auditory, olfactory, tactile, gustatory, proprioceptive and vestibular processing and shows high internal consistency with alphas ranging from .90 to .95 (Robinson, 2010).

\section{Procedure}

Ethical approval for the study was obtained from the local research ethics committee and informed parental consent was gained in order to proceed through the online questionnaire. Participants were also asked to provide their child's date of birth and diagnosed condition before beginning the questionnaires listed above. The DCDQ, AQ and SPCR were presented randomly in order to counterbalance the survey.

\section{Results}

Analysis Approach

Data were analysed using SPSS (version 24), and normality tests conducted on age using Skewness and Kurtosis outputs. Following tests for normality, demographic characteristics were established for age, gender and $A Q$ data using Bonferroni corrected independent t- 
tests between groups. Following this Bonferroni corrected independent t-tests were performed separately for DCDQ scores and SPCR scores in order to determine any significant differences between ASC and DCD. Cohen's $d$ was then calculated as an indicator of effect size, with 0.2 indicating a small, 0.5 medium and 0.8 a large effect. Where Cohen's $d$ was $>1$ the difference between the two means was considered larger than one standard deviation.

As a supplementary analysis ROC curves were performed on the significant differences found between ASC and DCD to assess the sensitivity and specificity of the findings. Post Hoc power analyses were conducted using EasyROC (Obuchowski, 2005) to ensure the sample size was large enough to guarantee a statistical power of at least 0.8 for each for each ROC curve.

Finally Pearson correlations between the $A Q$ and all sensorimotor measures (DCDQ and SPRC) were calculated for the ASC and DCD groups. Post Hoc power analyses were conducted using G*Power 3 (Faul, Erdfelder, Lang \& Buchner, 2007) to compute the achieved statistical power for each correlation.

\section{Do children with ASC show similar coordination difficulties to children with DCD?}

Table 2 shows results of comparisons between the ASC and DCD groups on coordination using the Developmental Coordination Disorder Questionnaire (DCDQ). Bonferroni corrected independent samples $t$-tests showed that there were no significant coordination differences between children with ASC and children with DCD. This was also the case in a secondary analysis between the smaller ASC with DCD group and the ASC group.

Table 2: Dependent variable descriptives and comparison of means.

\begin{tabular}{|c|c|c|c|c|}
\hline Group & $\begin{array}{l}\text { DCDQ } \\
\text { Fine Motor } \\
\text { Score }\end{array}$ & $\begin{array}{l}\text { DCDQ } \\
\text { Control of } \\
\text { Movement }\end{array}$ & $\begin{array}{c}\text { DCDQ } \\
\text { General } \\
\text { Co-ordination }\end{array}$ & $\begin{array}{l}\text { DCDQ Total } \\
\text { Score }\end{array}$ \\
\hline $\begin{array}{c}\mathrm{ASC} \\
(\mathrm{N}=42)\end{array}$ & $8.76 \pm 4.26$ & $15.60 \pm 5.73$ & $9.69 \pm 4.12$ & $33.81 \pm 11.24$ \\
\hline $\begin{array}{c}\mathrm{DCD} \\
(\mathrm{N}=26)\end{array}$ & $7.19 \pm 2.74$ & $16.04 \pm 5.43$ & $10.15 \pm 3.44$ & $33.38 \pm 8.29$ \\
\hline Difference & $\begin{array}{c}t(66)=1.848 \\
p=.069\end{array}$ & $\begin{array}{c}t(66)=.316 \\
p=.753\end{array}$ & $\begin{array}{c}t(66)=.479 \\
p=.634\end{array}$ & $\begin{array}{c}t(64)=.179 \\
p=.859\end{array}$ \\
\hline $\begin{array}{c}\text { ASC/DCD } \\
(\mathrm{N}=9)\end{array}$ & $9.11 \pm 4.73$ & $15.22 \pm 3.60$ & $7.89 \pm 3.14$ & $32.22 \pm 9.76$ \\
\hline
\end{tabular}




$\begin{array}{ccccc}\text { Difference } & t(49)=.219, & t(49)=.187, & t(49)=1.233, & t(49)=.392, \\ p=.827 & p=.853 & p=.224 & p=.696\end{array}$

Bonferroni corrected $p$ value $=.013$

\section{Do children with ASC show different sensory responsivity to children with DCD?}

Table 3 shows results of comparisons between the ASC and DCD groups on sensory measures. Independent samples $t$-tests showed that children with ASC had significantly higher: visual processing sensitivity $(t(42)=3.184, p=.003, d=.99)$; auditory processing sensitivity $(t(42)=3.010, p=.004, d=.94)$; and olfactory processing $(t(41)=2.049, p=.047$, $d=.64)$; whilst also having significantly lower sensitivity to proprioception $(t(42)=2.528$, $p=.015, d=.78$ ), than the DCD group, all with medium to large effect sizes.

Table 3: Dependent variable descriptives and comparison of means.

\begin{tabular}{|c|c|c|c|c|c|c|c|}
\hline Group & $\begin{array}{l}\text { SPCR } \\
\text { Visual }\end{array}$ & $\begin{array}{l}\text { SPCR } \\
\text { Auditory }\end{array}$ & $\begin{array}{l}\text { SPCR } \\
\text { Tactile }\end{array}$ & $\begin{array}{l}\text { SPCR } \\
\text { Olfactory }\end{array}$ & $\begin{array}{l}\text { SPCR } \\
\text { Gustatory }\end{array}$ & $\begin{array}{c}\text { SPCR } \\
\text { Proprioception }\end{array}$ & $\begin{array}{l}\text { SPCR } \\
\text { Vestibular }\end{array}$ \\
\hline $\begin{array}{c}\text { ASC } \\
(N=26)\end{array}$ & $40.92 \pm 17.20$ & $39.96 \pm 17.67$ & $37.27 \pm 19.43$ & $17.81 \pm 11.76$ & $14.38 \pm 8.55$ & $30.77 \pm 17.60$ & $24.80 \pm 13.67$ \\
\hline $\begin{array}{c}\text { DCD } \\
(\mathrm{N}=18)\end{array}$ & $.83 \pm 15.36$ & $24.67 \pm 14.80$ & $28.56 \pm 16.50$ & $10.12 \pm 12.45$ & $12.22 \pm 9.82$ & $43.94 \pm 16.08$ & $20.50 \pm 12.77$ \\
\hline ifference & $\begin{array}{c}t(42)=3.184 \\
p=.003^{\star} \\
d=1.0\end{array}$ & $\begin{array}{c}t(42)=3.010 \\
p=.004^{*} \\
d=0.9\end{array}$ & $\begin{array}{c}t(42)=1.553 \\
p=.128\end{array}$ & $\begin{array}{c}t(41)=2.049 \\
p=.047 \\
d=0.6\end{array}$ & $\begin{array}{c}t(42)=.776 \\
p=.442\end{array}$ & $\begin{array}{c}t(42)=2.528 \\
p=.015 \\
d=0.8\end{array}$ & $\begin{array}{c}t(41)=1.046 \\
p=.302\end{array}$ \\
\hline
\end{tabular}

Note: Effect size: $0.2=$ small, $0.5=$ medium, $0.8=$ large. ${ }^{*}$ Bonferroni corrected $p$ value $=.007$

\section{Supplementary analysis of validity in using visual, auditory, proprioceptive processing and $A Q$ as a possible consideration towards differential diagnosis}

In the independent t-tests, visual, auditory and proprioception were shown to be significantly different between ASC and DCD to large effect, when applying a statistical power $\geq 0.8$. Using the sum score of visual and auditory sensitivity and a negative score of proprioception (possible - actual: due to a positive score being more indicative of DCD) as the independent predictor, where condition type was the dependent variable, these modalities were assessed through a receiver operating characteristics $(R O C)$ curve in order to explore diagnostic validity for the difference between ASC and DCD conditions. 
The area under the curve (AUC) is a measure of the overall predictive validity where $\mathrm{AUC}=0.50$ signals random prediction, $0.60<\mathrm{AUC} \leq 0.70$ poor, $0.70<\mathrm{AUC} \leq 0.80$ fair, $0.80<A \cup C \leq 0.90$ good and AUC>0.90 excellent validity (Metz, 1978). The ROC curve for increased auditory and visual sensitivity, and decreased proprioception in comparison to DCD yielded an AUC of 0.87 , showing 'good' validity (Fig. 1).

A ROC curve (Fig. 2) plotting the sum of the $A Q$ (independent variable) and a diagnosis of ASC (dependent variable) yielded an AUC of 0.93 , showing 'excellent' validity. The best cut-off score on the AQ to help distinguish between DCD and ASC, that maximises (sensitivity + specificity) is 89.5 . At this score, the sensitivity is .85 and the specificity is .84 $(1$ - specificity $=.16)$. This indicates that the $A Q$ continues to be an excellent screener for ASC when compared to DCD symptoms, however these results suggest that the cut-off point between these two conditions should be increased from that considered typical for controls at 76 , to 90 for those presenting with possible DCD.

Figure 1: A Receiver operating characteristics curve for the relationship between the sum of Auditory / Visual and Proprioceptive questions on the SPRC and a diagnosis of ASC from a population of ASC and DCD children (area under curve 0.87)
Figure 2: A Receiver operating characteristics curve for the relationship between the sum of Autism Quotient questions and a diagnosis of ASC from a population of ASC and DCD children (area under curve 0.93).

NB Post Hoc power analyses conducted using EasyROC (Obuchowski, 2005) ensured sample sizes achieved at least 0.8 statistical for each ROC curve.
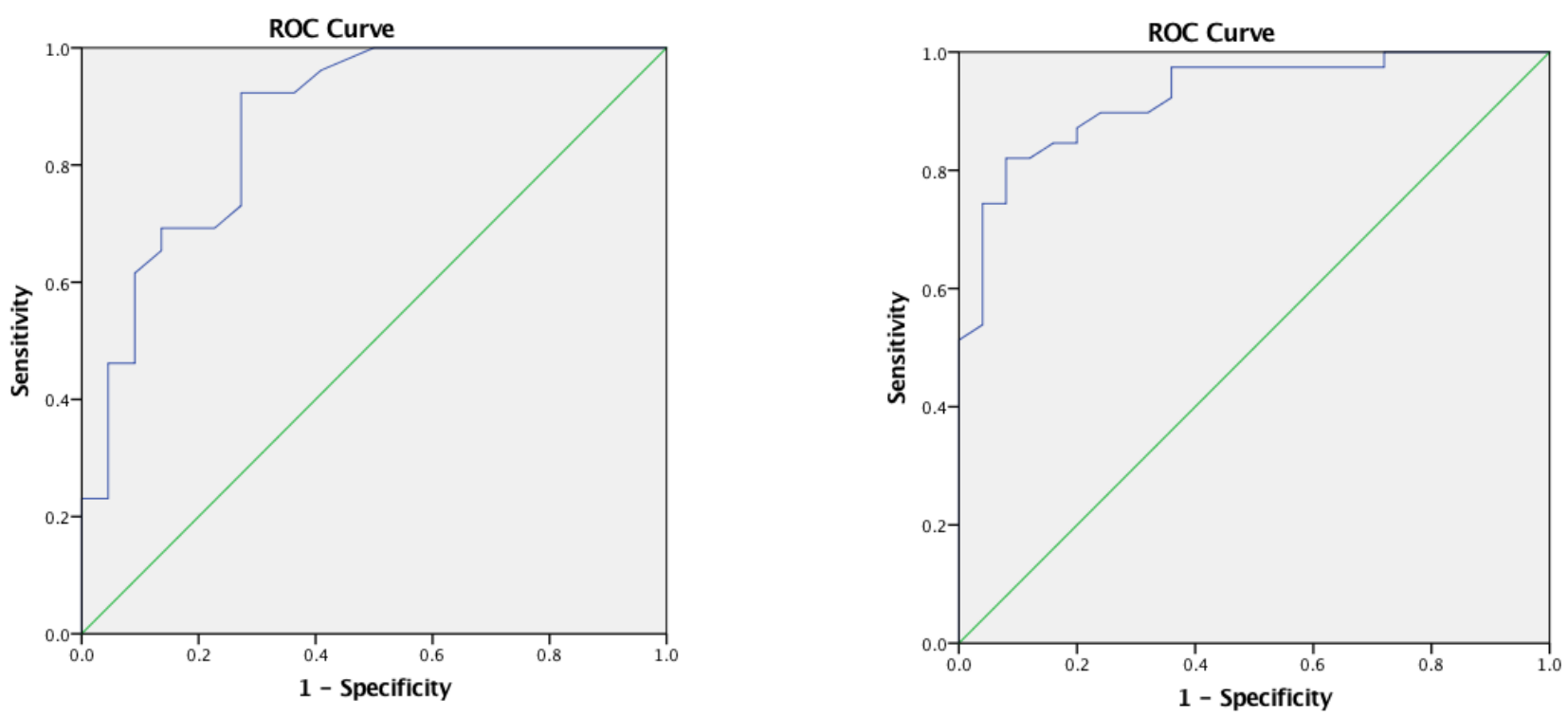

Are the autism symptoms in both DCD and ASC associated with coordination and sensory 
No correlations were shown between motor coordination scores and $A Q$ scores in $D C D$ or ASC. Table 4 shows results of the sensory responsivity correlation analysis. In the ASC group ( $\mathrm{n}=26$ ), when statistical power was taken into consideration no significant colinearity was shown between the autism measures $(A Q)$ and the sensory modalities, with visual, auditory and olfactory sensitivity indicating significant association but with limited power (<.6) (visual: $r=.348, p=.041$; auditory: $r=.531, p=.003$; olfactory: $r=.388, p$ $=.025)$. However, in the DCD group $(n=18)$ visual, tactile and vestibular sensitivity all correlated significantly with autism symptoms when the power was $\geq .8$ (visual $r=.777, p<$ .001 ; tactile $r=.736, p<.001$; vestibular $r=.753, p<.001$ ), with all other modalities also indicating significance.

Table 4: Correlation analysis (r) for autism symptoms (AQ) and sensory responsivity (SPCR) in ASC and DCD.

\begin{tabular}{|c|c|c|c|c|c|c|c|}
\hline \multicolumn{8}{|c|}{ Sensory Profile Checklist Revised } \\
\hline & Vision & Auditory & Tactile & Olfactory & Gustatory & Proprioception & Vestibular \\
\hline \multicolumn{8}{|c|}{ ASC $n=26$} \\
\hline AQ TOTAL & $.348^{\star}$ & $.531^{* *}$ & .321 & $.388^{*}$ & .173 & .286 & .312 \\
\hline \multicolumn{8}{|c|}{ DCD $n=18$} \\
\hline AQ TOTAL & $.777^{\star *}$ & $.703^{* *}$ & $.736^{\star *}$ & $.548^{*}$ & $.609^{* *}$ & $.560^{* *}$ & $.753^{\star *}$ \\
\hline
\end{tabular}

Note: ${ }^{*} p<.05,{ }^{* *} p<.01,{ }^{* * *} p<.001$. Required $r=>.736$ for sample size and $\alpha .05$ to achieve Statistical Power $=.8$ Correlations in bold indicate results $>$ required effect size

\section{Discussion}

This study aimed to examine the similarities and differences in coordination and sensory responsivity between DCD and ASC. Our results showed that when using the parent reported developmental coordination disorder questionnaire (DCDQ: Wilson et al., 2007) no significant differences in coordination were found between ASC and DCD, suggesting that the two conditions can often present with broadly similar coordination difficulties. Additionally, a smaller group of children who had a dual diagnosis of ASC and DCD also demonstrated no difference in coordination presentation. However, our results did show some significant differences in sensory responsivity between ASC and DCD, in increased 
visual and auditory responsivity and decreased proprioception. Furthermore, when summed together these differences showed good validity in identifying the diagnosis of each condition.

Results support previous findings that show ASC have motor impairment, such as that by Dziuk et al., (2007), Green et al., (2009), Liu and Breslin (2013) and McPhillips, Finley, Bejerot and Hanley (2014), and further substantiates claims that ASC is in fact a movement disorder (Leary and Hill, 1996; Fournier et al., 2010; Gillberg \& Kadesjö, 2003). However, these results perhaps challenge the validity of a dual diagnosis of ASC and DCD: with movement difficulties in ASC being so prevalent and co-occurring, is there a need for a dual diagnosis, or should there be an acceptance of movement difficulties in ASC?

The differences in sensory responsivity support our hypothesis that visual responsivity and proprioception would differ between conditions. This hypothesis was derived from literature that proposed different underlying causes for motor coordination difficulties, in which the formation of a feedforward program, form coherence and spatial processing are associated with DCD, and sensory feedback, motion coherence and visual sensitivity, with ASC. This finding is important in that it emphasises different features within the conditions, whilst also helping to discriminate between them. Moreover, this finding adds crosssyndrome evidence to present literature that attempts to identify the aetiology of each condition. Thus, perhaps aiding diagnosis whilst also defining intervention, for example therapy that focuses specifically on visual behaviour in ASC and proprioception in DCD. However, in addition to visual sensitivity being increased in the ASC condition, auditory sensitivity was also shown to be significantly greater in ASC than DCD. Moreover, research has already shown that sound therapy can be a successful intervention in ASC (AbediKoupaei, Poushaneh, Mohammadi \& Sioampour, 2013; Ross \& Balasubramaniam, 2015; Hall \& Case-Smith, 2007). The aforementioned theories in underlying sensorimotor patterns do not include auditory responsivity, however the regulation of visual movement has been associated with the auditory spatial channel and locus of sound (Butterworth \& Castillo, 1976; Perrott, Saberi, Brown \& Strybel, 1990), more specifically it is thought that visual and auditory signals converge directly onto the neurons projecting to the eye and head premotor centres (Goldring, Dorris, Corneil, Ballantyne \& Munoz, 1996). For this 
reason the connection between these modalities unquestionably requires further investigation.

In addition to differences in sensory responsivity, the $A Q$ also continued to show excellent validity as a screener distinguishing between ASC and DCD, however our analyses would indicate that a higher cut-off point of 90 should be considered as opposed to the 76 presently designated for typically developing individuals, thus taking into account some of the similarities between the conditions. It is also noteworthy that sensory responsivity appears to significantly correlate with the $A Q$ for children with $D C D$, but not for children with ASC. This may indicate that any relationship between sensory processing and autism symptoms is limited and subject to levels of sensory responsivity.

A limitation of the current study is that it includes only online parent reported data. For example, despite the DCDQ (Wilson et al., 2007) being validated with the Movement ABC (Henderson, Sugden \& Barnett, 2007), it is a subjective checklist and further objective testing would help corroborate results. Additionally, although the ROC curves were subject to Post Hoc power analyses to ensure the sample size was large enough to guarantee a statistical power of at least 0.8 for each ROC curve, these were exploratory analyses in order to improve assessment and intervention for each condition and would benefit from a larger sample size. Finally, both the $D C D Q$ and $A Q$ have a ceiling age younger than some participants. However, the questionnaires were used as scales to create a profile, in a similar fashion to the Sensory Profile Checklist revised, not as a screener or diagnostic measure. Furthermore only two participants were greater than 16 years of age (one from ASC and one from DCD).

In conclusion, this study suggests the presentation of coordination difficulties in children with ASC is very similar to those with DCD and should be treated as such. However the sensory profiles between the conditions do differ in that children with ASC have greater auditory and visual sensitivity, whilst children with DCD have greater proprioceptive sensitivity. These differences show 'good' specificity and sensitivity in this study and could be considered as a diagnostic aid when discriminating between the two conditions. These differences also agree with the literature in the apparent underlying causes of motor coordination difficulties in both conditions, such that ASC coordination difficulties are reportedly linked to visual processing impairments: whilst DCD coordination difficulties 
appear to be linked to spatial processing. However, auditory processing sensitivity was also identified in the ASC sensory profile as a difference between the two movement conditions. This may also be related to the visual modality and the relationship between the two modalities warrants further investigation. In addition to a different sensory profile, the $A Q$ also appears to discriminate between the two conditions with 'excellent' specificity and sensitivity, however it is proposed that a higher cut-off point is taken into consideration for children with DCD in order to allow for co-occurring presentations in the two conditions. It is hoped that this study may not only help to discriminate between two often phenotypically similar conditions, but in doing so has furthered knowledge into the underlying difficulties of the conditions and ultimately their therapy.

\section{Acknowledgements.}

This work was funded by the Centre for Research in Psychology, Behaviour and Achievement, Coventry University, UK.

The Autism Research Centre (ARC) University of Cambridge, UK

Local Support groups and Parents

Olga Bogdashina

References

1. AbediKoupaei, M., Poushaneh, K., Mohammadi, A. Z., \& Siampour, N. (2013). Sound therapy: An experimental study with autistic children. Procedia-Social and Behavioral Sciences, 84, 626-630.

2. American Psychiatric Association. (1987). Diagnostic and statistical manual of mental disorders (3rd ed.). Washington, DC: Author

3. American Psychiatric Association. (2013). Diagnostic and statistical manual of mental disorders (5th ed.). Washington, DC: Author 
4. Asperger, H. (1944). Die „Autistischen Psychopathen” im Kindesalter. European Archives of Psychiatry and Clinical Neuroscience, 117(1), 76-136.

5. Auyeung, B., Baron-Cohen, S., Wheelwright, S., \& Allison, C. (2008). The autism spectrum quotient: Children's version (AQ-Child). Journal of autism and developmental disorders, 38(7), 1230-1240.

6. Baron-Cohen, S., Wheelwright, S., Skinner, R., Martin, J., \& Clubley, E. (2001). The autism-spectrum quotient $(A Q)$ : Evidence from asperger syndrome/highfunctioning autism, malesand females, scientists and mathematicians. Journal of autism and developmental disorders, 31(1), 5-17.

7. Berkeley, S. L., Zittel, L. L., Pitney, L. V., \& Nichols, S. E. (2001). Locomotor and object control skills of children diagnosed with autism. Adapted Physical Activity Quarterly, 18(4), 405-416.

8. Blanche, E. I., Reinoso, G., Chang, M. C., \& Bodison, S. (2012). Proprioceptive processing difficulties among children with autism spectrum disorders and developmental disabilities. American Journal of Occupational Therapy, 66(5), 6214

9. Blank, R., Smits- Engelsman, B. O. U. W. I. E. N., Polatajko, H., \& Wilson, P. (2012). European Academy for Childhood Disability (EACD): Recommendations on the definition, diagnosis and intervention of developmental coordination disorder (long version). Developmental Medicine \& Child Neurology, 54(1), 54-93.

10. Bogdashina, O. (2016). Sensory perceptual issues in autism and asperger syndrome: different sensory experiences-different perceptual worlds. Jessica Kingsley Publishers.

11. Brooks, V. B. (1983). Motor Control How Posture and Movements are Governed. Physical Therapy, 63(5), 664-673.

12. Butterworth, G., \& Castillo, M. (1976). Coordination of auditory and visual space in newborn human infants. Perception, 5(2), 155-160. 
13. Cairney, J., Rigoli, D., \& Piek, J. (2013). Developmental coordination disorder and internalizing problems in children: the environmental stress hypothesis elaborated. Developmental Review, 33(3), 224-238.

14. Caminha, R. C., \& Lampreia, C. (2012). Findings on sensory deficits in autism: implications for understanding the disorder. Psychology \& Neuroscience, 5(2), 231-237.

15. Cantell, M. H., Smith, M. M., \& Ahonen, T. (1994). Clumsiness in adolescence: Educational, motor and social outcomes of motor delay, detected at five years. Adapted Physical Activity Quarterly, 11, 115-129.

16. Cassidy, S., Hannant, P., Tavassoli, T., Allison, C., Smith, P., \& Baron-Cohen, S. (2016). Dyspraxia and autistic traits in adults with and without autism spectrum conditions. Molecular Autism, 7(1), 48.

17. Chang, S. H., \& Yu, N. Y. (2010). Characterization of motor control in handwriting difficulties in children with or without developmental coordination disorder. Developmental Medicine \& Child Neurology, 52(3), 244-250.

18. Chawarska K, Paul R, Klin A, Hannigen S, Dichtel LE, Volkmar F (2007). Parental recognition of developmental problems in toddlers with autism spectrum disorders. J Autism Dev Disord 37(1):62-72. doi:10.1007/ s10803-006-0330-8 27.

19. Cherng, R. J., Hsu, Y. W., Chen, Y. J., \& Chen, J. Y. (2007). Standing balance of children with developmental coordination disorder under altered sensory conditions. Human movement science, 26(6), 913-926.

20. Chung, C., \& Khuu, S. K. (2014). The processing of coherent global form and motion patterns without visual awareness. Frontiers in psychology, 5, 195.

21. Conson, M., Mazzarella, E., Frolli, A., Esposito, D., Marino, N., Trojano, L., ... \& Grossi, D. (2013). Motor imagery in Asperger syndrome: testing action simulation by the hand laterality task. PloS one, 8(7), e70734. 
22. Cummins, A., Piek, J. P., \& Dyck, M. J. (2005). Motor coordination, empathy, and social behaviour in school- aged children. Developmental Medicine \& Child Neurology, 47(7), 437-442.

23. Deconinck, F. J., De Clercq, D., Savelsbergh, G. J., Van Coster, R., Oostra, A., Dewitte, G., \& Lenoir, M. (2006). Differences in gait between children with and without developmental coordination disorder. Motor Control, 10(2), 125-142.

24. Deconinck, F. J., Spitaels, L., Fias, W., \& Lenoir, M. (2009). Is developmental coordination disorder a motor imagery deficit?. Journal of Clinical and Experimental Neuropsychology, 31(6), 720-730.

25. Denckla, M. B. (1984). Developmental dyspraxia: The clumsy child. Middle childhood: Development and dysfunction, 245-260.

26. Dewey, D., Kaplan, B. J., Crawford, S. G., \& Wilson, B. N. (2002). Developmental coordination disorder: associated problems in attention, learning, and psychosocial adjustment. Human movement science, 21(5), 905-918.

27. Dowd, A. M., McGinley, J. L., Taffe, J. R., \& Rinehart, N. J. (2012). Do planning and visual integration difficulties underpin motor dysfunction in autism? A kinematic study of young children with autism. Journal of autism and developmental disorders, 42(8), 1539-1548.

28. Dziuk MA, Larson JC, Apostu A, Mahone EM, Denckla MB, Mostofsky SH. Dyspraxia in autism: association with motor, social, and communica-tive deficits. Dev Med Child Neurol (2007) 49(10):734-9. doi:10.1111/ j.14698749.2007.00734.x

29. Faul, F., Erdfelder, E., Lang, A. G., \& Buchner, A. (2007). G* Power 3: A flexible statistical power analysis program for the social, behavioral, and biomedical sciences. Behavior research methods, 39(2), 175-191.

30. Flanagan JE, Landa R, Bhat A, Bauman M. Head lag in infants at risk for autism: a preliminary study. Am J Occup Ther (2012) 66(5):577-85. doi:10.5014/ajot.2012.004192 
31. Fournier KA, Hass CJ, Naik SK, Lodha N, Cauraugh JH. (2010). Motor coordination in autism spectrum disorders: a synthesis and meta-analysis. J Autism Dev Disord 40(10):1227-40. doi:10.1007/s10803-010-0981-3

32. Gagnon-Roy, M., Jasmin, E., \& Camden, C. (2016). Social participation and interventions supporting teenagers and young adults living with developmental coordination disorder (DCD): results from a Scoping Review. Child: Care, Health and Development, 42, 840-851.

33. Gheysen, F., Van Waelvelde, H., \& Fias, W. (2011). Impaired visuo-motor sequence learning in Developmental Coordination Disorder. Research in developmental disabilities, 32(2), 749-756.

34. Gibbs, J., Appleton, J., \& Appleton, R. (2007). Dyspraxia or developmental coordination disorder? Unravelling the enigma. Archives of disease in childhood, 92(6), 534-539.

35. Gidley Larson, J. C., Bastian, A. J., Donchin, O., Shadmehr, R., \& Mostofsky, S. H. (2008). Acquisition of internal models of motor tasks in children with autism. Brain, 131(11), 2894-2903.

36. Gillberg, C., \& Kadesjö, B. (2003). Why bother about clumsiness? The implications of having developmental coordination disorder (DCD). Neural plasticity, 10(1-2), 59-68.

37. Goldring, J. E., Dorris, M. C., Corneil, B. D., Ballantyne, P. A., \& Munoz, D. R. (1996). Combined eye-head gaze shifts to visual and auditory targets in humans. Experimental brain research, 111(1), 68-78.

38. Gowen, E., \& Hamilton, A. (2013). Motor abilities in autism: a review using a computational context. Journal of autism and developmental disorders, 43(2), 323-344.

39. Green D, Charman T, Pickles A, Chandler S, Loucas T, Simonoff E, et al. (2009). Impairment in movement skills of children with autistic spectrum disorders. Dev Med Child Neurol 51(4):311-6. doi:10.1111/j.1469-8749.2008.03242.x 13. 
40. Greenfield, K., Ropar, D., Smith, A. D., Carey, M., \& Newport, R. (2015). Visuotactile integration in autism: atypical temporal binding may underlie greater reliance on proprioceptive information. Molecular autism, 6(1), 51

41. Gubbay, S. S. (1975). The clumsy child: A study of developmental apraxic and agnosic ataxia (Vol. 5). WB Saunders C

42. Hall, L., \& Case-Smith, J. (2007). The effect of sound-based intervention on children with sensory processing disorders and visual-motor delays. American Journal of Occupational Therapy, 61(2), 209-215.

43. Hannant, P., Tavassoli, T., \& Cassidy, S. (2016). The role of sensorimotor difficulties in autism spectrum conditions. Frontiers in neurology, 7.

44. Hannant, P., Cassidy, S., Tavassoli, T., \& Mann, F. (2016). Sensorimotor Difficulties Are Associated with the Severity of Autism Spectrum Conditions. Frontiers in integrative neuroscience, 10.

45. Henderson, S. E., Sugden, D. A., \& Barnett, A. L. (2007). Movement assessment battery for children-2: Movement ABC-2: Examiner's manual. Pearson.

46. Hilton C, Wente L, LaVesser P, Ito M, Reed C, Herzberg G. (2007). Relationship between motor skill impairment and severity in children with Asperger syndrome. Res Autism Spectr Disord 1(4):339-49. doi:10.1016/j. rasd.2006.12.003 88. Piek JP, Dyck MJ. Sensory-motor

47. Hirata, S., Hideyuki, O., Kitajima, Y., Hosobuchi, T., Nakai, A., \& Kokubun, M. (2015). Relationship between Motor Skill Impairments and Motor Imagery Ability in Children with Autism Spectrum Disorders: A Pilot Study Using the Hand Rotation Task. Psychology, 6(6), 752.

48. Inui, N., \& Suzuki, K. I. (1998). Practice and serial reaction time of adolescents with autism. Perceptual and motor skills, 86(2), 403-410.

49. Izawa, J., Pekny, S. E., Marko, M. K., Haswell, C. C., Shadmehr, R., \& Mostofsky, S. H. (2012). Motor Learning Relies on Integrated Sensory Inputs in ADHD, but 
Over- Selectively on Proprioception in Autism Spectrum Conditions. Autism Research, 5(2), 124-136.

50. Jansiewicz EM, Goldberg MC, Newschaffer CJ, Denckla MB, Landa R, Mostofsky $\mathrm{SH}$. (2006). Motor signs distinguish children with high functioning autism and Asperger's syndrome from controls. J Autism Dev Disord 36(5):613-21. doi:10.1007/s10803-006-0109-y

51. Jeannerod, M., \& Decety, J. (1995). Mental motor imagery: A window into the representational stages of action. Current Opinion in Neurobiology, 5, 727-732.

52. Kanner, L. (1943). Autistic disturbances of affective contact. Nervous child , 2 (3), 217-250.

53. Kirby, A., Sugden, D., \& Purcell, C. (2014). Diagnosing developmental coordination disorders. Archives of disease in childhood, 99(3), 292-296.

54. Kopp S, Beckung E, Gillberg C. (2010). Developmental coordination disorder and other motor control problems in girls with autism spectrum disorder and/or attention-deficit/hyperactivity disorder. Res Dev Disabil 31(2):350-61. doi:10.1016/j.ridd.2009.09.017

55. Leary, M. R., \& Hill, D. A. (1996). Moving on: autism and movement disturbance. Mental retardation.

56. Lejeune, C., Catale, C., Willems, S., \& Meulemans, T. (2013). Intact procedural motor sequence learning in developmental coordination disorder. Research in Developmental Disabilities, 34(6), 1974-1981.

57. Lindsay, G., \& Dockrell, J. E. (2012). The relationship between speech, language and communication needs and behavioural, emotional and social difficulties.

58. Lingam, R., Hunt, L., Golding, J., Jongmans, M., \& Emond, A. (2009). Prevalence of developmental coordination disorder using the DSM-IV at 7 years of age: A UK population-based study. Pediatrics, 123(4), e693-e700. 
59. Liu, T., \& Breslin, C. M. (2013). Fine and gross motor performance of the MABC-2 by children with autism spectrum disorder and typically developing children. Research in Autism Spectrum Disorders, 7(10), 1244-1249.

60. MacDonald M, Lord C, Ulrich D. (2013). The relationship of motor skills and adaptive behavior skills in young children with autism spectrum disorders. Res Autism Spectr Disord 7(11):1383-90. doi:10.1016/j.rasd.2013.07.020

61. MacNeil, L. K., \& Mostofsky, S. H. (2012). Specificity of dyspraxia in children with autism. Neuropsychology, 26(2), 165.

62. Mandich, A. D., Polatajko, H. J., Macnab, J. J., \& Miller, L. T. (2001). Treatment of children with developmental coordination disorder: What is the evidence?. Physical \& Occupational Therapy in Pediatrics, 20(2-3), 51-68.

63. Marko, M. K., Crocetti, D., Hulst, T., Donchin, O., Shadmehr, R., \& Mostofsky, S. H. (2015). Behavioural and neural basis of anomalous motor learning in children with autism. Brain, 138(3), 784-797.

64. Masterton, B. A., \& Biederman, G. B. (1983). Proprioceptive versus visual control in autistic children. Journal of Autism and Developmental Disorders, 13(2), 141-152.

65. McCleery, J. P., Allman, E., Carver, L. J., \& Dobkins, K. R. (2007). Abnormal magnocellular pathway visual processing in infants at risk for autism. Biological psychiatry, 62(9), 1007-1014.

66. McPhillips, M., Finlay, J., Bejerot, S., \& Hanley, M. (2014). Motor Deficits in Children With Autism Spectrum Disorder: A Cross- Syndrome Study. Autism Research, 7(6), 664-676.

67. Metz CE. Basic principles of ROC analysis. Semin Nucl Med. 1978;8:283-298.

68. Miller, M., Chukoskie, L., Zinni, M., Townsend, J., \& Trauner, D. (2014). Dyspraxia, motor function and visual-motor integration in autism. Behavioural brain research, 269, 95-102. 
69. Milne, E., White, S., Campbell, R., Swettenham, J., Hansen, P., \& Ramus, F. (2006). Motion and form coherence detection in autistic spectrum disorder: Relationship to motor control and 2: 4 digit ratio. Journal of autism and developmental disorders, 36(2), 225-237.

70. Ming X, Brimacombe M, Wagner GC. (2007). Prevalence of motor impairment in autism spectrum disorders. Brain Dev 29(9):565-0. doi:101016/j. braindev.2007.03.002

71. Miyahara M, Tsujii M, Hori M, Nakanishi K, Kageyama H, Sugiyama T. (1997). Brief report: motor incoordination in children with Asperger syndrome and learning disabilities. J Autism Dev Disord 27(5):595-603. doi:10.1023/A:1025834211548 18.

72. Mosconi, M. W., Luna, B., Kay-Stacey, M., Nowinski, C. V., Rubin, L. H., Scudder, C., ... \& Sweeney, J. A. (2013). Saccade adaptation abnormalities implicate dysfunction of cerebellar-dependent learning mechanisms in autism spectrum disorders (ASD). PLoS One, 8(5), e63709.

73. Mostofsky, S.H.,Dubey, P., Jerath, V. K., Jansiewicz, E. M., Goldberg, M. C., and Denckla, M. B., (2006). Developmental dyspraxia is not limited to imitation in children with autism spectrum disorders._J. Int.Neuropsychol.Soc. 12, 31426.doi:10.1017/s1355617706060437

74. Nayate, A., Bradshaw, J. L., \& Rinehart, N. J. (2005). Autism and Asperger's disorder: are they movement disorders involving the cerebellum and/or basal ganglia?. Brain research bulletin, 67(4), 327-334.

75. Nazarali, N., Glazebrook, C. M., \& Elliott, D. (2009). Movement planning and reprogramming in individuals with autism. Journal of autism and developmental disorders, 39(10), 1401-1411.

76. O'brien, J., Spencer, J., Atkinson, J., Braddick, O., \& Wattam-Bell, J. (2002). Form and motion coherence processing in dyspraxia: evidence of a global spatial processing deficit. Neuroreport, 13(11), 1399-1402. 
77. Obuchowski, N. A. (2005). Fundamentals of clinical research for radiologists. Am. J. Roentgenol, 184, 364-372.

78. Page J, Boucher J. Motor impairments in children with autistic disorder. Child Lang Teach Ther (1998) 14(3):233-59. doi:10.1191/ 026565998673400901

79. Perrott, D. R., Saberi, K., Brown, K., \& Strybel, T. Z. (1990). Auditory psychomotor coordination and visual search performance. Attention, Perception, \& Psychophysics, 48(3), 214-226.

80.Piek, J. P., \& Dyck, M. J. (2004). Sensory-motor deficits in children with developmental coordination disorder, attention deficit hyperactivity disorder and autistic disorder. Human movement science, 23(3), 475-488.

81. Price, K. J., Shiffrar, M., \& Kerns, K. A. (2012). Movement perception and movement production in Asperger's Syndrome. Research in Autism Spectrum Disorders, 6(1), 391-398.

82. Ratcliffe, B., Wong, M., Dossetor, D., \& Hayes, S. (2015). The association between social skills and mental health in school-aged children with autism spectrum disorder, with and without intellectual disability. Journal of autism and developmental disorders, 45(8), 2487-2496.

83. Rinehart, N. J., Bradshaw, J. L., Brereton, A. V., \& Tonge, B. J. (2001). Movement preparation in high-functioning autism and Asperger disorder: a serial choice reaction time task involving motor reprogramming. Journal of autism and developmental disorders, 31(1), 79-88.

84. Robinson 2010 Thesis:

https://www.era.lib.ed.ac.uk/bitstream/handle/1842/5308/Thesis\%20final\%20print. pdf? sequence $=1$

85. Ross, J. M., \& Balasubramaniam, R. (2015). Auditory white noise reduces postural fluctuations even in the absence of vision. Experimental brain research, 233(8), 2357-2363. 
86. Schoemaker, M. M., \& Kalverboer, A. F. (1990). Treatment of clumsy children. Developmental biopsychology. Experimental and observational studies in children at risk.

87. Siaperas, P., Ring, H. A., McAllister, C. J., Henderson, S., Barnett, A., Watson, P., \& Holland, A. J. (2012). Atypical movement performance and sensory integration in Asperger's syndrome. Journal of autism and developmental disorders, 42(5), 718725.

88. Smits-Engelsman, B. C. M., Wilson, P. H., Westenberg, Y., \& Duysens, J. (2003). Fine motor deficiencies in children with developmental coordination disorder and learning disabilities: An underlying open-loop control deficit. Human movement science, 22(4), 495-513.

89. Spencer, J., O'brien, J., Riggs, K., Braddick, O., Atkinson, J., \& Wattam-Bell, J. (2000). Motion processing in autism: evidence for a dorsal stream deficiency. Neuroreport, 11(12), 2765-2767.

90. Sugden, D. A., \& Chambers, M. E. (2003). Intervention in children with developmental coordination disorder: the role of parents and teachers. British journal of educational psychology, 73(4), 545-561.

91. Teitelbaum P, Teitelbaum O, Nye J, Fryman J, Maurer RG. Movement analysis in infancy may be useful for early diagnosis of autism. Proc Natl Acad Sci U S A (1998) 95(23):13982-7. doi:10.1073/pnas.95.23.13982

92. Tomchek, S. D., \& Dunn, W. (2007). Sensory processing in children with and without autism: a comparative study using the short sensory profile. American Journal of occupational therapy, 61(2), 190-200.

93. Tsai, C. L. (2009). The effectiveness of exercise intervention on inhibitory control in children with developmental coordination disorder: using a visuospatial attention paradigm as a model. Research in developmental disabilities, 30(6), 1268-1280.

94. Tsiotra, G. D., Flouris, A. D., Koutedakis, Y., Faught, B. E., Nevill, A. M., Lane, A. M., \& Skenteris, N. (2006). A comparison of developmental coordination disorder 
prevalence rates in Canadian and Greek children. Journal of Adolescent Health, 39(1), 125-127.

95. Vandenbroucke, M. W., Scholte, S. H., Engeland, H. V., Lamme, V. A., \& Kemner, C. (2009). A new approach to the study of detail perception in Autism Spectrum Disorder (ASD): Investigating visual feedforward, horizontal and feedback processing. Vision research, 49(9), 1006-1016.

96. Wall, A. E., Reid, G., \& Paton, J. (1990). The syndrome of physical awkwardness. Advances in Psychology, 74, 283-316.

97.Wang, T. N., Tseng, M. H., Wilson, B. N., \& Hu, F. C. (2009). Functional performance of children with developmental coordination disorder at home and at school. Developmental Medicine \& Child Neurology, 51(10), 817-825.

98. World Health Organization. (1992). Specific developmental disorder of motor function F82. In International Classification of Diseases (pp. 250-252). World Health Organization Geneva.

99. Whyatt, C. P, Craig, C.M. (2012) Motor skills in children aged 7-10 years, diagnosed with autism spectrum disorder. J Autism Dev Disord 42(9):1799-809. doi:10.1007/s10803-011-1421-8 19.

100. Williams, J., Thomas, P. R., Maruff, P., \& Wilson, P. H. (2008). The link between motor impairment level and motor imagery ability in children with developmental coordination disorder. Human Movement Science, 27(2), 270-285.

101. Wilson, B. N., Crawford, S. G., Green, D., Roberts, G., Aylott, A., \& Kaplan, B. J. (2009). Psychometric properties of the revised developmental coordination disorder questionnaire. Physical \& occupational therapy in pediatrics, 29(2), 182202.

102. Wilson, B. N., Kaplan, B. J., Crawford, S. G., \& Roberts, G. (2007). The developmental coordination disorder questionnaire 2007 (DCDQ'07). Administrative manual for the DCDQ107 with psychometric properties. 
103. Wilson, P. H., Maruff, P., Butson, M., Williams, J., Lum, J., \& Thomas, P. R. (2004). Internal representation of movement in children with developmental coordination disorder: a mental rotation task. Developmental medicine and child neurology, 46(11), 754-759.

104. Wilson, P. H., Ruddock, S., Smits- Engelsman, B. O. U. W. I. E. N., Polatajko, H., \& Blank, R. (2013). Understanding performance deficits in developmental coordination disorder: a meta- analysis of recent research. Developmental Medicine \& Child Neurology, 55(3), 217-228.

105. Zoia, S., Pelamatti, G., Cuttini, M., Casotto, V., \& Scabar, A. (2002). Performance of gesture in children with and without DCD: effects of sensory input modalities. Developmental Medicine \& Child Neurology, 44(10), 699-705. 